\title{
Crusher Plates
}

\section{For Diamonds}

\author{
by R. S. Young
}

\begin{abstract}
A LARGE proportion of the world's output of in$A$ dustrial diamonds is sold to users in the form of crushed boart. The term boart is applied to the dull gray, green, or yellow diamonds found in many fields. Frequently they have an opaque coating and sometimes have twin structures, slip planes, or corrugated skin. The dark color and inclusions in these diamonds make them unsuitable for gem purposes, and their imperfect and weak crystal structure usually renders them unfit for wire drawing dies, wheel dressers, and lathe tools. Boart, the lowest-priced category of industrial diamonds, is chiefly employed in drill bits and grinding wheels, where its unique hardness and abrasion resistance have resulted in widespread use.

Boart is received at the sorting offices of the distributing organization serving the leading industrial diamond producers in sizes ranging from 1 to $40 \mathrm{~mm}$ diam. It is crushed to pass through a Tyler No. 7 mesh sieve, which has an opening about $2.8 \mathrm{~mm}$. A laboratory-type jaw crusher, similar to those used for ore samples, and a roll crusher, are employed. Since the object in crushing is to leave the diamond particles in the largest size possible, below 7 mesh, jaw crushing is the major operation. The use of the roll crusher, with hardened steel rolls, may be considered a secondary procedure applicable only to those diamonds whose shape has allowed them to pass through the jaw crusher without sufficient reduction.
\end{abstract}

The jaw crusher plates have to withstand the impact and abrasion of diamond. The usual type of unalloyed white cast iron jaw plates wore away so rapidly that they had to be replaced after crushing only 50,000 carats in some cases. In addition, the quantity of abraded iron that had to be separated with a magnet from the diamond powder made this operation tedious. Manganese steel jaw plates, having about 13 pct manganese, gave a vastly increased life, crushing about 900,000 carats before replacement was required. Manganese steel, however, is nonmagetic and since the small quantity of abraded steel could not be removed from the boart with a magnet, allowance had to be made for this by giving the purchaser a slightly higher caratage than ordered.

About a year ago, on the recommendation of the Diamond Research Laboratory, the abrasion-resist-

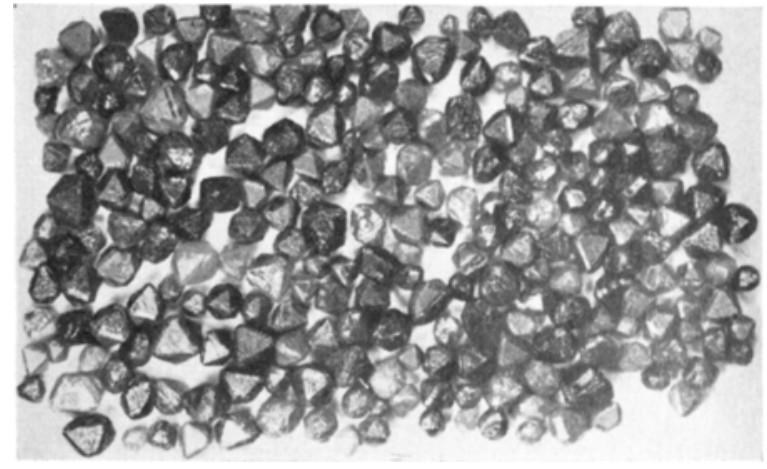

Crown jewels of industry-Industrial diamonds that must be crushed for grinding wheels, drill bits, and other diamond tools.

ant nickel-chromium white cast iron known as $\mathrm{Ni}$-Hard was employed for these jaw plates. The Type I or regular type of Ni-Hard with the following nominal composition was employed: 3.25 pct $\mathrm{C}$, 0.50 pet $\mathrm{Si}, 0.50$ pet $\mathrm{Mn}, 0.1$ pet $\mathrm{S}, 0.3$ pet $\mathrm{P}, 4.25$ pct $\mathrm{Ni}$, and 1.75 pct $\mathrm{Cr}$. The $\mathrm{Ni}-\mathrm{H}$ ard plates were chill cast, and were stress relieved by drawing at $400^{\circ} \mathrm{F}$ for $4 \mathrm{hr}$.

The results have been satisfactory. Life has been slightly better than that of manganese steel, the NiHard plates crushing about $1,000,000$ carats before replacement is necessary. Since Ni-Hard is less expensive than manganese steel, the replacement cost is considerably lower. A far greater advantage, however, is that the small quantity of abraded $\mathrm{Ni}$ Hard can be removed from the boart by magnetic separation.

This is the severest condition of operation in the world for jaw crusher plates. The terrific impact and abrasive forces encountered in diamond crushing may be visualized when it is recalled that the quantity of $1,000,000$ carats crushed in the life of such an abrasion-resistant material as a Ni-Hard jaw plate is only about $440 \mathrm{lb}$. This weight would represent, for the ordinary type of mine or smelter product, 100 to 150 samples.

R. S. YOUNG is Director of Research at Diamond Research Laboratory, Industrial Distributors (1946) Ltd., Johannesburg, South Africa. 